\title{
A Systematic Review of Human Papillomavirus Genotypes in Women With Normal Cervical Cytology: The Brazilian Paradigm
}

Ngozi Dom-Chima

University of Delaware

Esther Biswas-Fiss

University of Delaware

Subhasis Biswas ( $\square$ biswassb@udel.edu )

University of Delaware

\section{Research}

Keywords: HPV, HPV types, Prevalence, Distribution, Normal cervical Cytology, Brazil

Posted Date: July 6th, 2021

DOl: https://doi.org/10.21203/rs.3.rs-660503/v1

License: (c) (i) This work is licensed under a Creative Commons Attribution 4.0 International License.

Read Full License 


\section{Abstract}

Background: Human papillomavirus (HPV) family of viruses is the leading cause of cervical cancer in women worldwide. More than 67 types of HPV are known to infect humans, and their distribution varies from region to region. HPV prevalence studies in Brazil have focused on cervical cancer; however, a detailed understanding of HPV type prevalence in women with normal cervix is absent in the literature. Our primary aim is to systematically review the literature and summarize the prevalence and distribution of HPV types in Brazilian women with HPV positive but normal cervical cytology and lack observed abnormal cells on their cervix's surface upon cytology analysis.

Methods: This protocol was designed following the PRISMA-P guidelines. We conducted this systematic review with an active search in PubMed, Web of Science, and CINAHL databases and supplemented by a secondary screening of all included articles' reference lists. The search terms "Brazil", "HPV", "Human Papillomavirus", "prevalence", "distribution", "Human Papillomavirus types", and "normal cervical cytology" were used for screening the databases. Of 1048 articles retrieved and subjected to duplicates assessment, title and abstract assessment, and full-text assessment of eligibility, 11 articles were included in the review. We excluded articles from the male population, known cervical cancer cases, and studies with a sample size of $<15$. Qualitative assembly of the data and analysis was performed using GraphPad Prism 5.0

Results: The articles included in the study reported the prevalence of HPV types in women with normal cytology and HPV positive from ten Brazilian states. The total sample size ranged from 80 to 432, and the sample size for the HPV positive and normal cervical cytology group ranged from 28 to 209 . HPV prevalence ranged from 0 to $89.4 \%$, and a total of 43 HPV types were identified in the study population. There was variation between studies on the distribution of HPV types because of the detection and genotyping technique used and geographical location. HPV66 was the only HPV type detected in every study reviewed, regardless of geographical region and methods.

Conclusions: Due to variation in genotyping techniques used in these studies, HPV type prevalence and geographical distribution may be misestimated or underestimated. But results of these studies give a clear view of the total prevalence of HPV types in Brazil. It is also essential to consider the HPV types present in women with normal cervical cytology before the HPV-mediated progression to abnormal cervical lesions.

Systematic Review Registration: Prospective Register for Systematic Reviews (PROSPERO) registration CRD42020151655

\section{Background}

Human Papillomavirus (HPV) belongs to the Papillomaviridae family. There are over one hundred and fifty Alpha-papillomavirus identified in genital mucosa and cutaneous lesions in humans[1]. These Alphapapillomavirus HPV types are classified into low-risk HPV and high-risk HPV types based on their ability 
to cause genital benign lesions or cancer [2]. Low-risk HPV types which are associated with anogenital warts and benign epithelial lesions, includes HPV2, 3, 6, 7,10, 11, 13, 27, 28, 29, 32, 40, 42, 43, 44, 54, 57, $61,62,71,72,74,78,81,83,84,86,87,89,90,91$, and 94 . While high-risk HPV types HPV16, 18, 26, 30, $31,33,34,35,39,45,51,52,53,56,58,59,66,67,68,69,70,73,82$, and 85 can cause cancer like cervical, penile, throat, tongue, tonsils, and anal cancers. There are HPV types of Undetermined risk which includes HPV77, 97, 102, 106, 114, 117, 125, 160, and 177 [3].

In Brazil, with a population estimated at 210 million [4], about $5.4 \%$ of women in the population are estimated to have HPV infection and harbor at least two HPV types in their cervix at a given time[5]. Cervical cancer is the third most frequent cancer (excluding non-melanoma skin cancer) in women aged 15 to 44 years in Brazil. In 2018, the age-standardized incidence of cervical cancer was estimated at 12.2 per 100,000 women, and the mortality rate is estimated at 5.8 per 100000 women [4]. Across South America, cervical cancer mortality and incidence rates have shown to differ significantly among nations. For example, of the thirteen countries examined, Bolivia has the highest mortality rate of 19 per 100000 women, while French Guiana is 3.7 per 100000 women. Similarly, Bolivia has the highest incidence rate of 38.5 per 100000 women, while Brazil is 12.2 per 100000 women[6].

The high incidence and mortality rates can be attributed to various factors such as socioeconomic conditions, the conditions of medical facilities, or government support for the women's health that influences access to cervical cancer screening. These socioeconomic variables can lead to late diagnosis of cervical lesions and cancer [7], and thus, most studies that assessed the prevalence of HPV types in women, diagnosed at different grades of abnormal cervical lesions; cervical intraepithelial neoplasia-1 (CIN-1), CIN-2, CIN-3, and invasive cervical cancer[8-16].

Consequently, these socioeconomic variables propelled a limited number of studies focusing on the prevalence of HPV types in women with normal cervical cytology/HPV positive. No abnormal cells were observed on the surface of their cervix upon cytological analysis. It should be noted that the World Health Organization (WHO) recommends the standard practice of cervical cancer assessment is to screen women using a cervical cytology test (Pap test). WHO recommends that once a woman has been screened negative, she should not be rescreened for at least five years but should be rescreened within ten years $[17,18]$. However, results show that normal cervical cytology and HPV-positive women have a significantly higher risk of increased overall and type-specific HPV infection and CIN3 than double negative women $[19,20]$. This result suggests a lack of guidelines and care-management for HPV typespecific tests in women with normal cervical cytology and HPV positive.

Hence, this systematic review's primary objective is to summarize the prevalence and distribution of HPV types in Brazilian women who are HPV positive and have normal cervical cytology and assess any association between geographical location and distribution of HPV types.

\section{Methods}


A systematic review was conducted with an active search in the PubMed database, Web of Science, and the Cumulative Index to Nursing and Allied Health Literature (CINAHL) from June- July 2019. We used the search terms "Brazil", "HPV", "Human Papillomavirus", "prevalence", "distribution", "Human Papillomavirus types", and "normal cervical cytology" for searching the databases. Gender (women only) and language (English only) restrictions were also applied.

This study's inclusion criteria included published reports evaluating HPV infections in the cervix, evaluating HPV types in women with normal cervical cytological, and studies with clearly stated HPV detection and genotyping method. While exclusion criteria were HPV type-specific results from the male population, HPV type-specific results from known cervical cancer cases, studies with a sample size $<15$, and studies unrelated to the subject matter. Full-text Evaluation of the articles for final exclusion was carried out using the - NHLBI, NIH- Quality Assessment Tool for Observational Cohort, and Cross-Sectional Studies. We used this assessment tool to rate every article on a final score (poor, fair, or good). Two independent reviewers (ND and SB) evaluated the articles with a third-party tiebreaker (EB) to minimize the risk of bias.

Data extracted include publication authors, publication year, journal, study design, and location in Brazil. For the sample characteristics, we collected the age range of participants, the total number of samples, the total number of the HPV positive and normal cervical cytology group, pregnancy status, Human Immunodeficiency Virus (HIV) status, and sampling methods. We also collected HPV detection and genotyping techniques and the number of HPV types detected by the method.

We performed a qualitative assembly of the data by analyzing frequencies of individual HPV types. However, some articles presented the HPV type prevalence as frequencies, while others presented the HPV type prevalence as the whole number. Therefore, the HPV types presented as a whole number were converted to frequencies by dividing the number of HPV types by the total number of HPV types in the HPV positive and normal cervical cytology group. Due to variations in HPV detection and genotyping techniques and geographical locations, no effective statistical analysis was possible. High-risk and Lowrisk HPV types, not assessed in the studies, were reported in the HPV type-specific analysis to identify HPV type detection gaps. The analysis was performed using GraphPad Prism 5.0 to make visuals aids like graphs, flowcharts, and tables to aid the findings and interpretations.

\section{Results}

Out of 1048 articles originally retrieved from the database search, 800 articles were selected after duplicates were removed. Of the 800 articles, 57 were selected after the title and abstract analysis. After full-text assessment for eligibility, 11 articles met the inclusion criteria, while 46 articles were excluded with reasons presented in Fig. 1.

Eleven studies were included from ten states in Brazil: one study from the North region, Amazonas[21], four studies from the Northeast Region of Bahia, Sergipe, Maranhão, and Pernambuco[22-25], one from the Central-West region of Goais[26], four from the Southeast region of Minas Gerais, Rio De Janeiro, with 
two studies from Sao Paulo[27-29], and one from the South Region of Parana[30] Our results from each region are given below.

\section{North Region}

In the North region state of Amazonas, the participants' age range was 16-60 years. A total of 180 samples were obtained, and 48 were HPV positive/ normal cervical cytology and were obtained by cervical swab [21] (Table 1a).

Table 1a: Study Sample characteristics for the North region

\begin{tabular}{|c|c|c|c|}
\hline Reference & Age range & $\begin{array}{c}\text { No. of HPV positive/ normal } \\
\text { cytology in the total patient sample }\end{array}$ & Sampling method \\
\hline Costa-Lira et al, 2017 & $\leq 16$ to $60 \geq$ years & $48 / 180$ & Cervical swab \\
\hline
\end{tabular}

The molecular assay used in the study was a Polymerase chain reaction (PCR) based technique, with $26.7 \%$ of all identified Alphapapillomavirus HPV types were detected (Table 1 b). The only 22 HPV types detected includes High Risk HPV:16, 18, 31, 33, 52, 53, 58, 59, 66, 70, 82 and Low Risk HPV: 6, 54, 61, 62, $72,81,83,102$. HPV16 was the most detected

Table 1b: HPV detection and typing assay used in the North region.

\begin{tabular}{|c|c|c|c|}
\hline Reference & Location & $\begin{array}{c}\text { Percentage of HPV } \\
\text { positive/ normal } \\
\text { cytology samples }\end{array}$ & $\begin{array}{c}\text { Detection and typing } \\
\text { method }\end{array}$ \\
\hline Costa-Lira et al, $2017^{b}$ & Amazonas & $26.7 \%$ & PCR \\
\hline
\end{tabular}

\section{Northeast Region}

In the North region study, the participants' age range was 30-41.3 years. A total of 1325 samples were obtained, and 356 were HPV positive/ normal cervical cytology and included in this study. Cervical swab or cervical scraping sampling techniques were used to collect the samples (Table 2a).

Table 2a: Study Sample characteristics for the Northeast region 


\begin{tabular}{|c|c|c|c|}
\hline Reference & Age range & $\begin{array}{l}\text { No. of HPV positive/ normal cytology } \\
\text { in the total patient sample }\end{array}$ & Sampling method \\
\hline Brandao et al, 2009 & $\leq 19$ to $30 \geq$ years & $61 / 147$ & Cervical swab \\
\hline Bruno et al, $2014^{c}$ & N/A & $166 / 351$ & Cervical scraping \\
\hline Nascimento et al, 2018 & $\leq 30$ to $60>$ years & $35 / 395$ & Cervical swab \\
\hline Serra et al, 2018 & $<25-55>$ years & $94 / 432$ & Cervical swab \\
\hline $\begin{array}{l}\text { N/A Not available informatio } \\
\mathrm{a}_{\text {These studies included both preg }} \\
\mathrm{c}_{\text {These studies included sample }}\end{array}$ & $\begin{array}{l}\text { udy } \\
\text { on-pregnant women in the } \\
\text { in HIV+ }+ \text { - women in the }\end{array}$ & esize & \\
\hline
\end{tabular}

These studies used molecular assays for HPV detection and typing that included PCR-based technique, hybrid capture, PapilloCheck, linear array, and sequencing (Table 2b).

Table 2b: HPV detection and typing assay used in the Northeast region.

\begin{tabular}{|c|c|c|c|}
\hline Reference & Location & $\begin{array}{c}\text { Percentage of HPV positive/ } \\
\text { normal cytology samples }\end{array}$ & Detection and typing method \\
\hline Brandao et al, 2009 & Pernambuco & $41.5 \%$ & $\begin{array}{c}\text { MY09/MY11 PCR; Hybrid capture } \\
\text { II }\end{array}$ \\
\hline Bruno et al, 2014 & Bahia & $47.3 \%$ & PapilloCheck (Greiner Bio-One)] \\
\hline Nascimento et al, 2018 & Maranhao & $8.9 \%$ & GP5+/6+ PCR/ Linear Array \\
\hline Serra et al, 2018 & Sergipe & $21.8 \%$ & $\begin{array}{c}\text { GP5 }+/ 6+\text { and MY09/MY11 PCR; } \\
\text { PCR sequencing }\end{array}$ \\
\hline
\end{tabular}

In the Northeast Region states of Bahia, Sergipe, Maranhão, and Pernambuco, HPV16 was the most common across the region. However, different states in the region differed in the most prevalent HPV types. In Pernambuco, HPV16 was the most prevalent; in Bahia, HPV56 was the most prevalent; in Maranhão, HPV68 was the most prevalent, and in Sergipe, HPV16 was the most prevalent. (Fig. 3).

\section{Central region}

In the Central region of Goais, the study participants' age range was 17-61 years. A total number of 150 samples were obtained, and 48 were HPV positive/ normal cervical cytology and were obtained by cervical swab (Table 3a).

Table 3a: Study Sample characteristics for the Central region 


\begin{tabular}{|c|c|c|c|}
\hline Reference & Age range & $\begin{array}{c}\text { No. of HPV positive/ normal } \\
\text { cytology in the total patient } \\
\text { sample }\end{array}$ & Sampling method \\
\hline Cerquiera et al, $2007^{b}$ & $17-61$ years & $48 / 150$ & Cervical swab \\
\hline
\end{tabular}

The HPV detection and typing assay used in the study was a Polymerase chain reaction (PCR) based technique in combination with Restriction Fragment Length Polymorphism(RFLP), with $32 \%$ of all identified Alphapapillomavirus HPV types were detected (Table 3b). Identified 27 HPV types were as follows: High Risk HPV types: 16, 18, 31, 33, 35, 39, 52, 53,56, 58, 59, 66, 67, 68, 70, and Low-risk HPV: 6, $11,32,40,54,61,62,71,81$. Regarding the prevalence, Low-risk HPV81 was the most detected at the frequency of $21.6 \%$, contrary to common HPV16, which was detected at $13 \%$ (Figure 4).

Table 3b: HPV detection and typing assay used in the Central region.

\begin{tabular}{|c|c|c|c|}
\hline Reference & Location & $\begin{array}{c}\text { Percentage of HPV } \\
\text { positive/ normal cytology } \\
\text { samples }\end{array}$ & Detection and typing method \\
\hline Cerquiera et al, $2007^{b}$ & Goias & $32 \%$ & PCR/RFLP analysis \\
\hline
\end{tabular}

\section{Southeast region}

In the Southeast region states of Minas Gerais, Rio De Janeiro, and Sao Paulo, the study participants' age range was 39.5-46 years. A total number of 1207 samples were obtained by cervical swab and cervical scraping, and 379 samples were HPV positive/with normal cervical cytology and were processed further (Table 4a).

Table 4a: Study Sample characteristics for the Southeast region

\begin{tabular}{|c|c|c|c|}
\hline Reference & Age range & $\begin{array}{c}\text { No. of HPV positive/ normal } \\
\text { cytology in the total patient } \\
\text { sample }\end{array}$ & Sampling method \\
\hline Badial et al, 2018 ${ }^{b}$ & N/A & $42 / 80$ & Cervical swab \\
\hline Martins et al, 2016 & $14-95$ years & $209 / 431$ & Cervical scraping \\
\hline Miranda et al, 2012 & $<30-50>$ years & $44 / 399$ & Cervical swab \\
\hline Oliveira-Silva et al, 2011 & $25-59$ years & $84 / 297$ & Cervical swab \\
\hline $\begin{array}{l}\text { N/A Not available information in the study } \\
\text { b }\end{array}$ & \\
\hline
\end{tabular}


As the samples were analyzed by a combination of Nested PCR, Hybrid capture, RFLP, and sequencing for HPV detection and typing, but the common technique for all samples was a PCR-based technique (Table $4 b)$.

Table 4b: HPV detection and typing assay used in the Southeast region.

\begin{tabular}{|c|c|c|c|}
\hline Reference & Age range & $\begin{array}{c}\text { No. of HPV positive/ normal } \\
\text { cytology in the total patient } \\
\text { sample }\end{array}$ & Sampling method \\
\hline Badial et al, 2018 & N/A & $42 / 80$ & Cervical swab \\
\hline Martins et al, 2016 & $14-95$ years & $209 / 431$ & Cervical scraping \\
\hline Miranda et al, 2012 & $<30-50>$ years & $44 / 399$ & Cervical swab \\
\hline Oliveira-Silva et al, 2011 & $25-59$ years & $84 / 297$ & Cervical swab \\
\hline $\begin{array}{l}\text { N/A Not available information in the study } \\
\mathrm{b}_{\text {These studies included samples from HIv patients in the total sample size }}\end{array}$ \\
\hline
\end{tabular}

Based on the variety of the HPV detection and typing techniques used in each study, we observed differences in the frequencies in the HPV types detected. (Figure 5)

\section{South region}

In Parana's South region, the age range for the study participants was $25-55$ years. A total number of 418 samples were obtained by cervical swab, and 28 were found to be HPV positive/ normal cervical cytology and were analyzed for HPV types (Table 5a).

Table 5a: Study Sample characteristics for the South region

\begin{tabular}{|c|c|c|c|}
\hline Reference & Age range & $\begin{array}{c}\text { No. of HPV positive/ normal } \\
\text { cytology in the total patient } \\
\text { sample }\end{array}$ & Sampling method \\
\hline Da Silva et al, 2012 & $<25$ to $55 \geq$ years & $28 / 418$ & Cervical swab \\
\hline
\end{tabular}

The molecular assay used in the study was a PCR-based and Restriction Fragment Length Polymorphism(RFLP). Only $6.7 \%$ because of the HPV detection and typing techniques used. Of the HPV types were detected, which includes the following High-Risk HPV: $16,18,31,33,35,52,58,59,66,67,68$, 69, 70 and Low-Risk HPV: 6, 44, 55, 61, 72, 81, 83, 91 (Figure 6).

Table 5b: HPV detection and typing assay used in the South region. 


\begin{tabular}{|c|c|c|c|}
\hline Reference & Location & $\begin{array}{c}\text { Percentage of HPV } \\
\text { positive/ normal cytology } \\
\text { samples }\end{array}$ & Detection and typing method \\
\hline Da Silva et al, $2012^{a}$ & Parana & $6.7 \%$ & PCR/ RFLP analysis \\
\hline \multicolumn{4}{|c|}{ PCR: Polymerase chain reaction; RFLP: Restriction Fragment Length Polymorphism } \\
\hline
\end{tabular}

\section{Discussion}

HPV is known to be the major cause of cervical cancer and deaths in women worldwide[2]. HPV is a large family of viruses with more than 100 types of HPV is known. These HPV types appear to differ significantly in their propensity for oncogenesis. Even though HPV vaccines are now available, these vaccines are extremely limited in resisting only a few known HPV types that infect humans.

Furthermore, it appears that the HPV spectrum seems to be different in different regions of the world. Nonetheless, the extent of the HPV spectrum divergence from one region to another remains mostly in the dark due to a lack of adequate data and systematic investigation in that regard. This review is designed to elucidate the HPV spectrum in South America, focusing on Brazil.

In this review, we showed that HPV types: $6,11,32,40,42,43,44,54,57,61,62,71,72,74,78,81,83,84$, $89,90,91,16,18,26,31,33,35,39,45,51,52,53,56,58,59,66,67,68,69,70,73,82,02,114$ were found in women in Brazil in the absence of any cervical lesion. Besides, this review demonstrated that the most commonly detected HPV16 was not found in all Brazilian states. HPV66 was detected in all four regions of Brazil. In addition, in Sergipe state, only four HPV types, HPV16, 66, 6, and 71, were detected.

Conventional PCR-based methods were widely used in these studies in Brazil because of the specificity, sensitivity, and lower cost. However, PCR techniques detect only a few HPV types. Not all HPV genotypes present in a sample cannot detect all HPV types in patients with multiple HPV infections, which is quite common in certain demographics [31]. The Hybrid Capture ${ }^{\circledR} 2$, on the other hand, is a superior method as it can differentiate between many high-risk and low-risk types, but it still does not genotype all HPV types [32]. Several other methods used in these studies are commercial assays such as COBAS ${ }^{8} 4800$ and PapilloCheck ${ }^{\circledR}$ assay, which detects and genotypes only a single HPV type [33]. Consequently, these detection methodologies could not have identified all HPV types in these patient populations.

As most of these methods largely screen for only HPV16 and HPV18 because of their abundance and high risk of causing HSIL or underlying CIN2-3 or cancer. However, other non-16/18 high-risk HPV types are being lumped together and not individually evaluated. As stated earlier, there are more than one hundred fifty different HPV types. Studies show that a negative- HPV16/18 result does not necessarily exclude the possibility of HPV infection and future cytologic change, including cancer[34]. Individual evaluation of all HPV types is important for proper diagnosis. 
An interesting finding in our study is that many women in the age-range 14-25 years with normal cervical cytology were infected with both high-risk and low-risk HPV types. The International Agency for Research on Cancer (IARC) showed that women aged 25-65 + with normal cervical cytology had high-risk and lowrisk HPV types [35]. However, this age-specific HPV prevalence results seen in Brazilian women are not unusual in the age group. Nevertheless, in the United States of America, the American Cancer Society's recommendation for cancer screening using pap smear tests begins at age 25[36]. This recommendation does not fit with the Brazilian population. Women are infected with HPV as early as 14 years old, demonstrating that Pap smear screening would have to be recommended early.

In this review, we analyzed all available data derived from a variety of HPV detection and genotyping methods in 11 published reports. These studies may have excluded some HPV types, particularly in multiple infections, due to limitations of various detection methodologies. These limitations of described methodologies can be addressed more effectively with a more sensitive and specific technique, such as next-generation sequencing. Some studies included women that are HIV positive, as well as some who are HIV negative women in the study populations making the results more complex. These may have altered the HPB distribution since HIV-positive populations can be immuno-compromised, increasing the chances of multiple HPV infections. Furthermore, some of the studies examined both women with normal and abnormal cytology, which could have added to the sample population's diversity of interest.

\section{Conclusion}

Comprehensive characterization of all HPV types in the state or country population is critical to evaluating the HPV spectrum and their oncogenic potential. Modern techniques with a broad and accurate HPV diagnosis like next-generation sequencing will help determine the region's HPV diversity. With the observed frequency of HPV56, HPV68, and HPV81 in Brazil, the current 9-valent HPV vaccine that protects against HPV $6,11,16,18,31,33,45,52$, and 58 is inadequate for determining HPV diversity in a region.. This finding also suggests the need for a new generation, perhaps region-specific, vaccines that will be more effective. In this review, we have demonstrated the need for more research for determining the HPV spectrum in various regions of the world.,

\section{Abbreviations}

CIN: Cervical intraepithelial neoplasia; CINAHL: Cumulative Index to Nursing and Allied Health Literature; EB: Esther Biswas-Fiss; HIV: Human Immunodeficiency Virus HR: High Risk; HSIL: high grade squamous intraepithelial lesion; IARC: International Agency for Research on Cancer; LR: Low Risk; ND: Ngozi DomChima; NHLBI: National Heart, Lung, And Blood Institute; NIH: National Institutes of Health; PCR: Polymerase chain reaction; PRISMA: Preferred Reporting Items for Systematic Reviews and MetaAnalyses; SB: Subhasis Biswas; RFLP: Restriction Fragment Length Polymorphism

\section{Declarations}


Ethics approval and consent to participate.

Not Applicable

Consent for publication

Not Applicable

Availability of data and materials

All data generated and analyzed during this study are included in this article.

Competing interests

Not Applicable

Funding

Not Applicable

Author's contributions

ND and SB conceived the study and reviewed the literature. ND performed the literature search, extracted data from the literature, and prepared the manuscript's draft. SB and EB critically reviewed the manuscript. All Authors read and approved the final manuscript.

Acknowledgments

Not Applicable

\section{References}

1. PaVE: Papilloma virus genome database. https://pave.niaid.nih.gov/\#explore/reference_genomes/human_genomes. Accessed 17 Dec 2019.

2. Burk RD, Harari A, Chen Z. Human papillomavirus genome variants. Virology. 2013;445:232-43.

3. World Health Organization IA for R on C. Human papillomaviruses. IARC. monographs programme on the evaluation of carcinogenic risks to humans. 2007.

4. (No Title). http://gco.iarc.fr/today/data/factsheets/populations/76-brazil-fact-sheets.pdf. Accessed 20 Feb 2020.

5. I. Key data on HPV and HPV-related cancers. www.hpvcentre.net. Accessed 17 Dec 2019.

6. Ferlay J, Colombet M, Soerjomataram I, Mathers C, Parkin DM, Piñeros M, et al. Estimating the global cancer incidence and mortality in 2018: GLOBOCAN sources and methods. International Journal of Cancer. 2019;144:1941-53. doi:10.1002/ijc.31937. 
7. Barcelos MRB, Lima R de CD, Tomasi E, Nunes BP, Duro SMS, Facchini LA. Quality of cervical cancer screening in Brazil: external assessment of the PMAQ. Rev Saude Publica. 2017;51:67.

8. Amorim AT, Marques LM, Campos GB, Lobão TN, de Souza Lino V, Cintra RC, et al. Co-infection of sexually transmitted pathogens and Human Papillomavirus in cervical samples of women of Brazil. BMC Infect Dis. 2017;17.

9. Ribeiro AA, Figueiredo Alves RR, Costa MC, Villa LL, Zeferino LC, Mauricette Derchain SF, et al. Association between HPV types and species groups and cervical neoplasia from a high-risk area for cervical cancer, Goiĝnia, Brazil. Int J Gynecol Pathol. 2011;30:288-94.

10. Cavalcanti SM, Deus FC, Zardo LG, Frugulhetti IC, Oliveira LH. Human papillomavirus infection and cervical cancer in Brazil: a retrospective study. Mem Inst Oswaldo Cruz. 91:433-40. doi:10.1590/s0074-02761996000400009.

11. Clifford GM, Rana RK, Franceschi S, Smith JS, Gough G, Pimenta JM. Human papillomavirus genotype distribution in low-grade cervical lesions: Comparison by geographic region and with cervical cancer. Cancer Epidemiol Biomarkers Prev. 2005;14:1157-64.

12. Oliveira LHS, Rosa MLG, Pereira CRN, Vasconcelos GALBM, Silva RA, Barrese TZ, et al. Human papillomavirus status and cervical abnormalities in women from public and private health care in Rio de Janeiro State, Brazil. Rev Inst Med Trop Sao Paulo. 2006;48:279-85.

13. Resende LS de A, Rabelo-Santos SH, Sarian LO, Alves RRF, Ribeiro AA, Zeferino LC, et al. A portrait of single and multiple HPV type infections in Brazilian women of different age strata with squamous or glandular cervical lesions. BMC Infect Dis. 2014;14:214. doi:10.1186/1471-2334-14-214.

14. Rama CH, Roteli-Martins CM, Derchain SFM, Longatto-Filho A, Gontijo RC, Sarian LOZ, et al. Prevalência do HPV em mulheres rastreadas para o câncer cervical. [Prevalence of genital HPV infection among women screened for cervical cancer]. Rev Saude Publica. 2008;42:123-30. doi:10.1590/S0034-89102008000100016.

15. [Human papillomavirus cervical infection: viral genotyping and risk factors for high-grade squamous intraepithelial lesion and cervix cancer]. - PubMed - NCBI. https://www.ncbi.nlm.nih.gov/pubmed/21271154. Accessed 18 Dec 2019.

16. Jesus SP de, Costa ACM da, Barcellos RB, Medeiros RM de, Silva CMD da, Rossetti ML. A high prevalence of human papillomavirus 16 and 18 co-infections in cervical biopsies from southern Brazil. Brazilian J Microbiol. 2018;49:220-3.

17. WHO guidelines WHO guidelines for screening and treatment of precancerous lesions for cervical cancer prevention.

18. WHO | Guidelines for the prevention and control of cervical cancer. https://www.who.int/reproductivehealth/topics/cancers/hpv-vaccination/en/. Accessed 21 Feb 2020.

19. Polman NJ, Veldhuijzen NJ, Heideman DAM, Snijders PJF, Meijer CJLM, Berkhof J. HPV-positive women with normal cytology remain at increased risk of CIN3 after a negative repeat HPV test. Br J Cancer. 2017;117:1557-61. 
20. Fröberg M, Östensson E, Belkić K, Oštrbenk A, Poljak M, Mints M, et al. Impact of the human papillomavirus status on the development of high-grade cervical intraepithelial neoplasia in women negative for intraepithelial lesions or malignancy at the baseline: A 9-year Swedish nested casecontrol follow-up study. Cancer. 2019;125:239-48. doi:10.1002/cncr.31788.

21. Costa-Lira E, Jacinto AHVL, Silva LM, Napoleão PFR, Barbosa-Filho RAA, Cruz GJS, et al. Prevalence of human papillomavirus, Chlamydia trachomatis, and Trichomonas vaginalis infections in Amazonian women with normal and abnormal cytology. Genet Mol Res. 2017;16. doi:10.4238/gmr16029626.

22. Brandao VCRAB, Lacerda HR, Lucena-Silva N, Ximenes RA de A. Frequency and types of human papillomavirus among pregnant and non-pregnant women with human immunodeficiency virus infection in Recife determined by genotyping. Mem Inst Oswaldo Cruz. 2009;104:755-63.

23. Bruno A, Serravalle K, Travassos AG, Lima BG de C. [Genotype distribution of human papillomavirus in women from the state of Bahia, Brazil]. Rev Bras Ginecol Obstet. 2014;36:416-22. doi:10.1590/so100-720320140004995.

24. Nascimento M do DSB, Vidal FCB, Silva MACN da, Batista JE, Lacerda Barbosa M do C, Muniz Filho WE, et al. Prevalence of human papillomavirus infection among women from quilombo communities in northeastern Brazil. BMC Womens Health. 2018;18:1. doi:10.1186/s12905-017-0499-3.

25. Serra IGSS, Araujo ED, Barros GS, Santos FLSG, Gurgel RQ, Batista MVA. Prevalence of human papillomavirus types associated with cervical lesions in Sergipe state, Northeastern Brazil: high frequency of a possibly carcinogenic type. Epidemiol Infect. 2018;146:1184-93.

26. Cerqueira DM, Moraes DDS, Camara GNL, Amaral FA, Oyama CNR, Dos Santos MQC, et al. High HPV genetic diversity in women infected with HIV-1 in Brazil. Arch Virol. 2007;152:75-83. doi:10.1007/s00705-006-0828-6.

27. Badial RM, Dias MC, Stuqui B, Melli PPDS, Quintana SM, Bonfim CMD, et al. Detection and genotyping of human papillomavirus (HPV) in HIV-infected women and its relationship with HPV/HIV co-infection. Medicine (Baltimore). 2018;97:e9545.

28. Martins TR, de Oliveira CM, Rosa LR, de Campos Centrone C, Rodrigues CL, Villa LL, et al. HPV genotype distribution in Brazilian women with and without cervical lesions: correlation to cytological data. Virol J. 2016;13:3.

29. Miranda PM, Pitol BC, Moran MS, Silva NN, Felix PM, Lima-Filho JL, et al. Human papillomavirus infection in Brazilian women with normal cervical cytology. Genet Mol Res. 2012;11:1752-61.

30. da Silva MC, Martins HP, de Souza JL, Tognim MC, Svidzinski TI, Teixeira JJ, et al. Prevalence of HPV infection and genotypes in women with normal cervical cytology in the state of Parana, Brazil. Arch Gynecol Obstet. 2012;286:1015-22.

31. Brandstetter T, Böhmer S, Prucker O, Bissé E, zur Hausen A, Alt-Mörbe J, et al. A polymer-based DNA biochip platform for human papilloma virus genotyping. J Virol Methods. 2010;163:40-8.

32. Allali J, Chauve C, Denise A, Drevet C, Ferraro P, Gautheret D, et al. BRASERO: A resource for benchmarking RNA secondary structure comparison algorithms. Adv Bioinformatics. 2012;2012:5. 
33. Abreu ALP, Souza RP, Gimenes F, Consolaro MEL. A review of methods for detect human Papillomavirus infection. Virology Journal. 2012;9:262.

34. Demarco M, Lorey TS, Fetterman B, Cheung LC, Guido RS, Wentzensen N, et al. Risks of CIN 2+, CIN $3+$, and Cancer by Cytology and Human Papillomavirus Status: The Foundation of Risk-Based Cervical Screening Guidelines. J Low Genit Tract Dis. 2017;21:261-7. doi:10.1097/LGT.0000000000000343.

35. Human Papillomavirus and Related Diseases Report BRAZIL. www.hpvcentre.net. Accessed 13 Mar 2020.

36. The American Cancer Society Guidelines for the Prevention and Early Detection of Cervical Cancer. https://www.cancer.org/cancer/cervical-cancer/detection-diagnosis-staging/cervical-cancerscreening-guidelines.html. Accessed 16 Nov 2020.

\section{Figures}




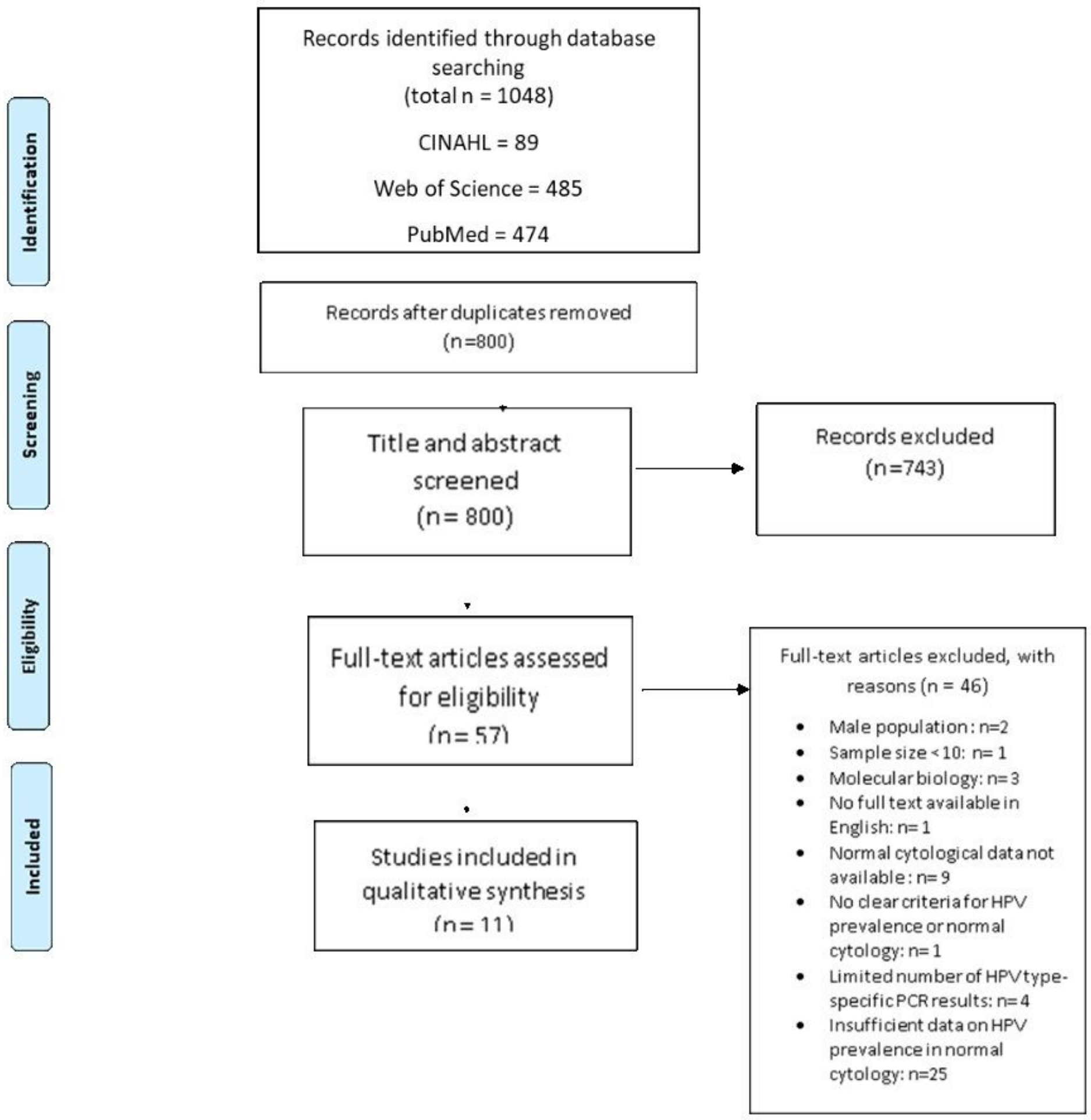

Figure 1

The PRISMA Flow diagram of the inclusion and exclusion process. PRISMA Flow Diagram Adapted from Moher D, Liberati A, Tetzlaff J, Altman DG, The PRISMA Group (2009). Preferred Reporting Items for Systematic Reviews and Meta-Analyses: The PRISMA Statement. PLoS Med 6(7): e1000097. doi:10.1371/journal.pmed1000097 

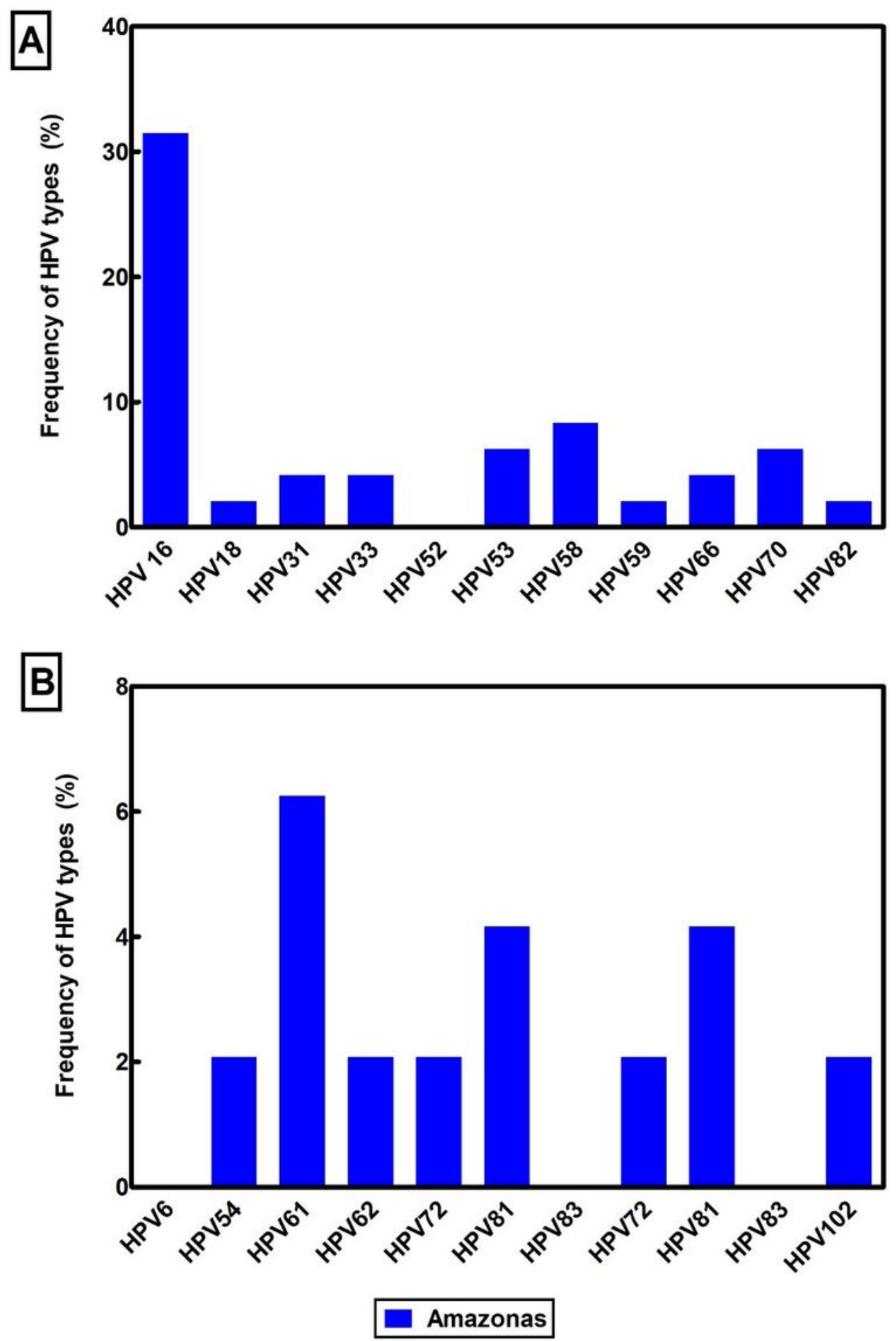

Figure 2

Frequency of HPV types in normal cervical cytology/HPV positive in a sample of women in the North Region (A) Frequency of high-risk HPV types. (B) Frequency of low-risk HPV types 

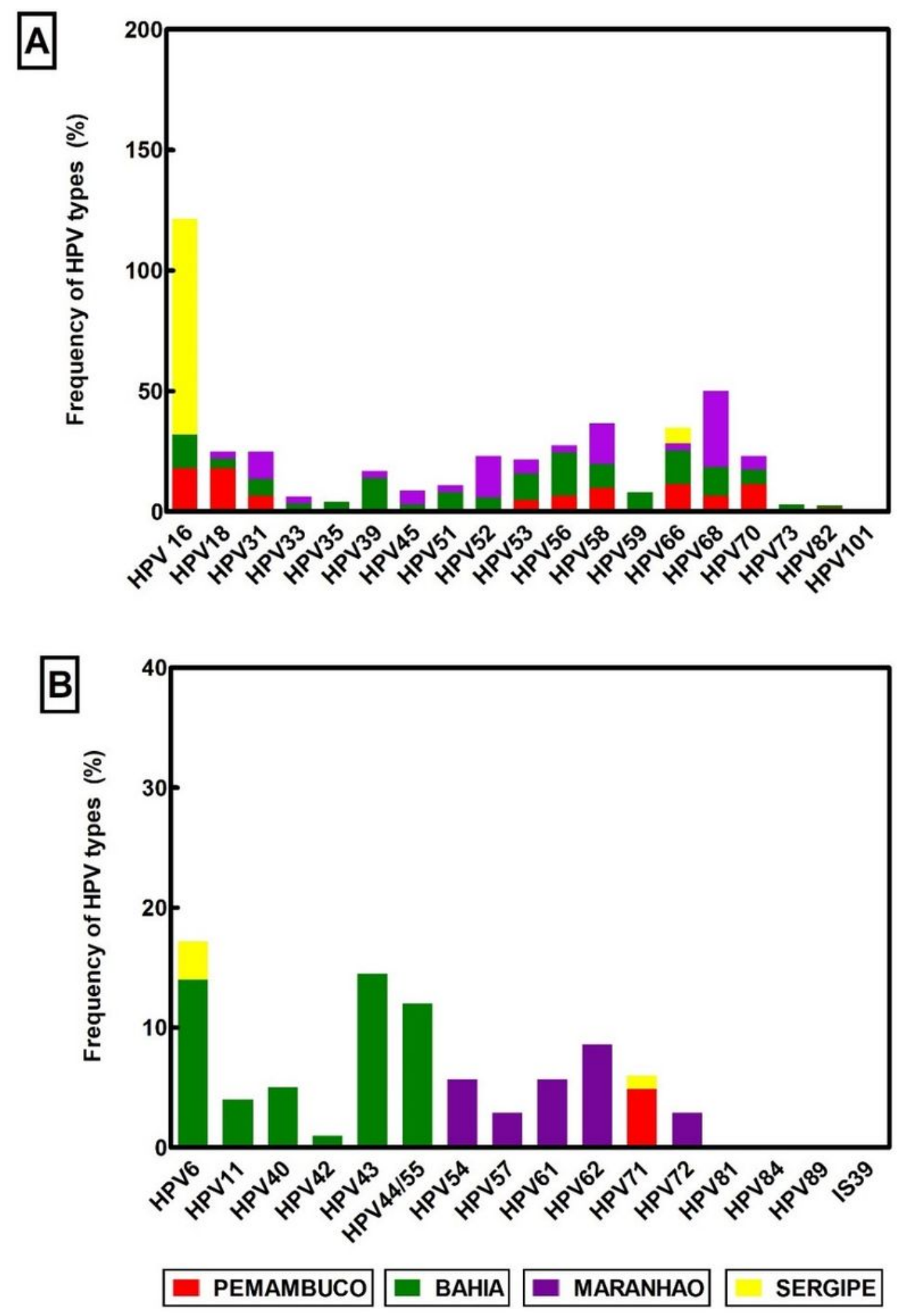

Figure 3

Frequency of HPV types in normal cervical cytology/HPV positive in a sample of women in the Northeast Region. (A) Frequency of high-risk HPV types. (B) Frequency of low-risk HPV types. 

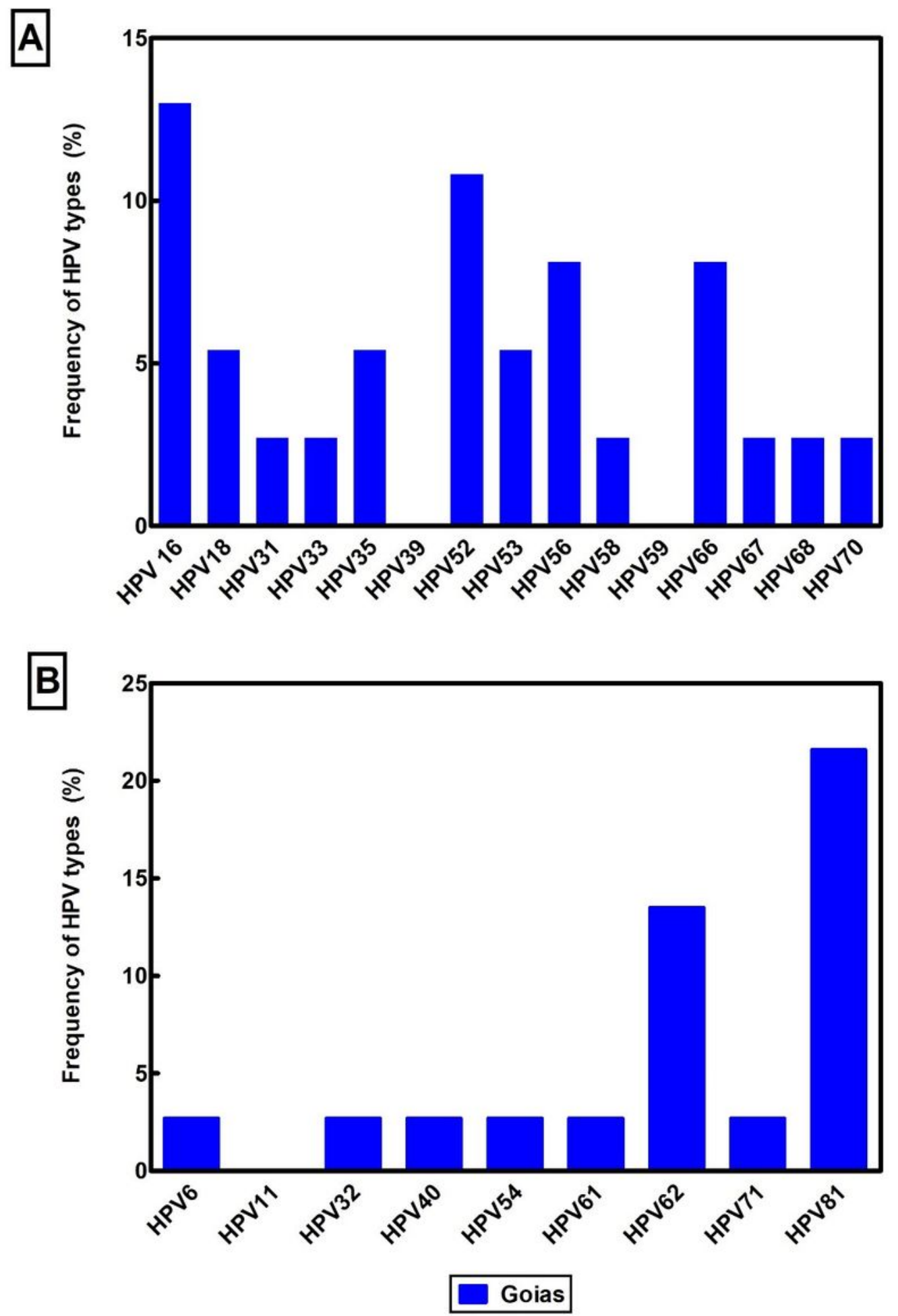

Figure 4

Frequency of HPV types in normal cervical cytology/HPV positive in a sample of women in the Central Region (A) Frequency of high-risk HPV types. (B) Frequency of low-risk HPV types. 

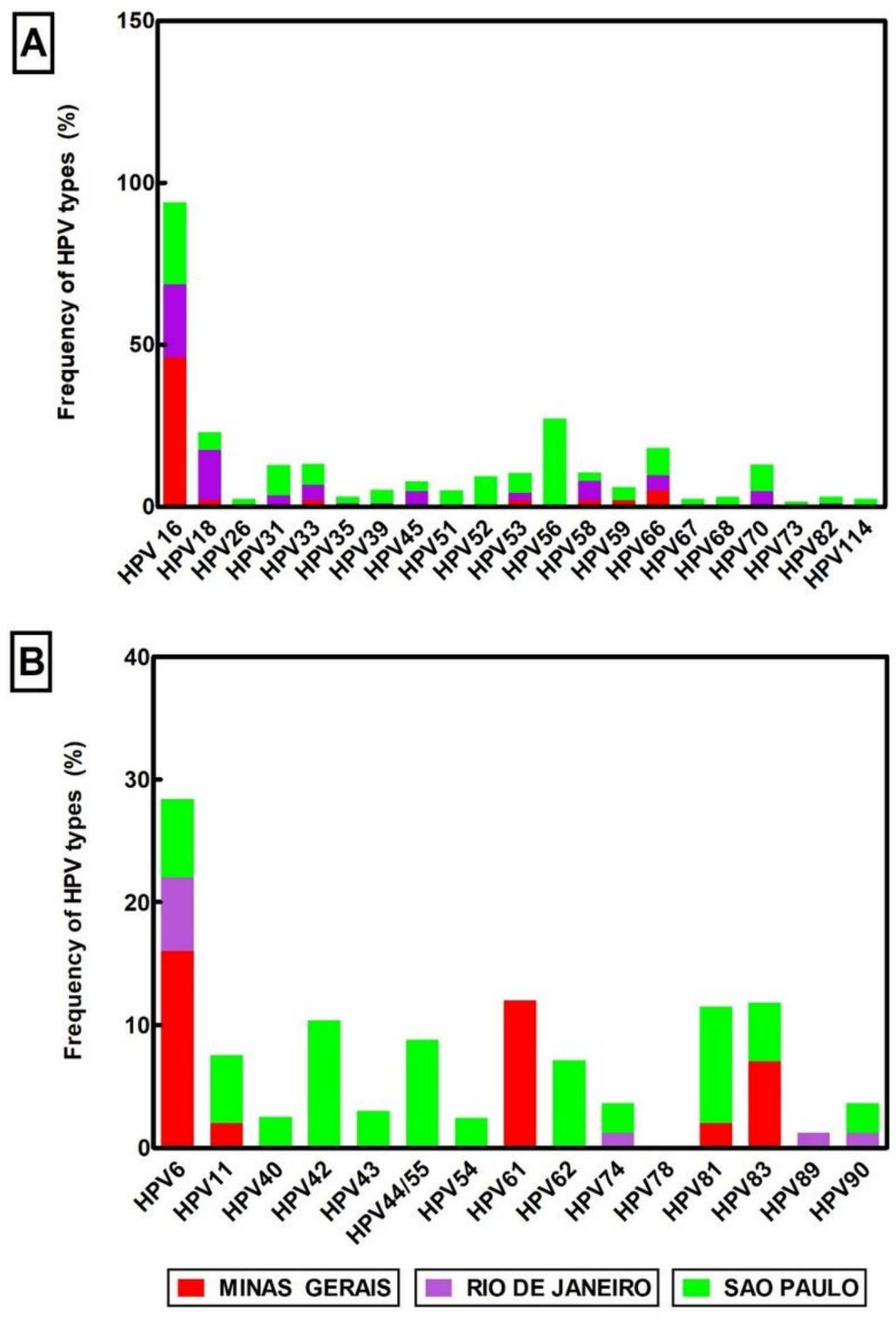

Figure 5

Frequency of HPV types in normal cervical cytology/HPV positive in a sample of women in the Southeast Region (A) Frequency of high-risk HPV types. (B) Frequency of low-risk HPV types. 

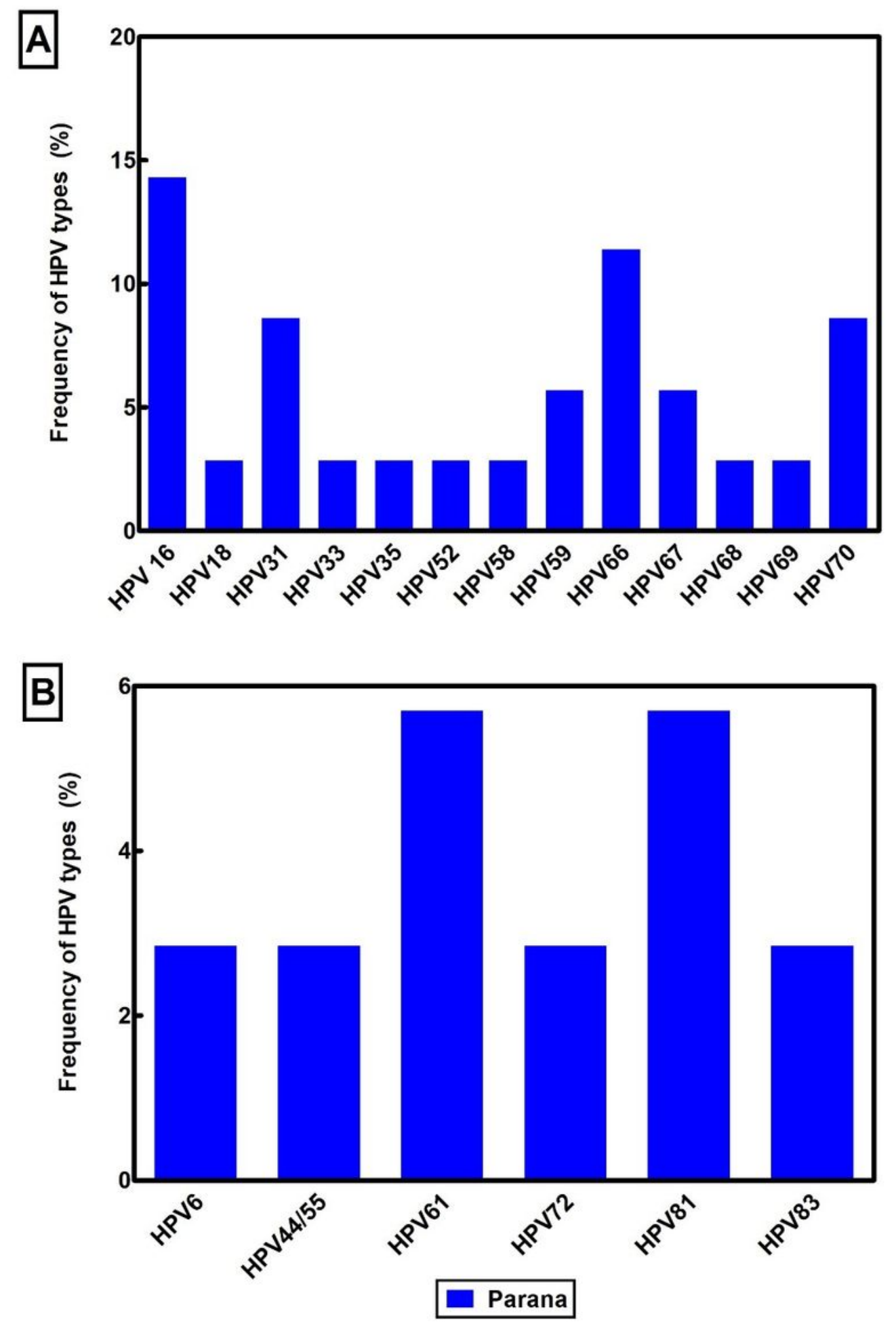

Figure 6

Frequency of HPV types in normal cervical cytology/HPV positive in a sample of women in the South Region (A) Frequency of high-risk HPV types. (B) Frequency of low-risk HPV types.

\section{Supplementary Files}


This is a list of supplementary files associated with this preprint. Click to download.

- PRISMAflowdiagram.docx

- PRISMAPchecklistBRAZILIANSTUDY.docx

- RESULTSOFQUALITYASSESSMENT.docx 